\title{
QTL Analysis of Adventitious Root Formation in Common Bean under Contrasting Phosphorus Availability
}

\author{
Ivan E. Ochoa, Matthew W. Blair, and Jonathan P. Lynch*
}

\begin{abstract}
Low phosphorus availability is a primary constraint to crop production in developing countries. Adventitious roots play an important role in phosphorus acquisition, as they are localized near the soil surface where phosphorus is relatively abundant. A population of recombinant inbred lines of Phaseolus vulgaris L. (G2333/G19839) was screened under high- and low-phosphorus conditions in the greenhouse and field. We observed phenotypic variation and transgressive segregation for adventitious root traits in both environments. Allometric analysis revealed that although the taproot and basal roots are closely linked to shoot growth, recombinant inbred line (RILs) differ substantially in biomass allocation for adventitious roots. A linkage map with 149 genetic markers and a total cumulative map length of $1175 \mathrm{cM}$ was used to identify a total of 19 QTL across 8 of the 11 linkage groups. Together these quantitative trait loci (QTL) accounted for 19 to $61 \%$ of the total phenotypic variation for adventitious root traits in the field and 18 to $39 \%$ under greenhouse conditions. Two major QTL for adventitious rooting under low phosphorus conditions in the field were observed on linkage groups B2 and B9 that together accounted for $61 \%$ of the observed phenotypic variation. We conclude that adventitious rooting under low phosphorus is a feasible target for bean breeding.
\end{abstract}

$\mathrm{C}$ OMMON bean is the most important legume for direct human consumption in the world. For over 500 million people in Latin America and Africa, common bean is an important source of nutrients and dietary protein (Broughton et al., 2003; Graham and Ranalli, 1997). Low soil fertility is a primary constraint to common bean production in many developing countries, affecting at least $80 \%$ of global bean production (CIAT, 2001; Wortmann et al., 1998). Of the several edaphic stresses affecting bean production, low phosphorus availability is the most important limitation, affecting over half of all bean production area in Africa and Latin America (Wortmann and Allen, 1994). Substantial genetic variation exists within common bean for growth under low phosphorus conditions (Lynch and Beebe, 1995). Cultivated bean accessions are less sensitive to low phosphorus availability than their wild ancestors (Lynch and Beebe, 1995). This suggests that the tolerance observed in cultivated common bean probably evolved after plant domestication where early landraces were moved from their original environment into phosphorus-deficient environments (Beebe et al., 1997; Gerloff and Gabelman, 1983; Lynch and Beebe, 1995).

I.E. Ochoa and J.P. Lynch, Department of Horticulture, The Pennsylvania State University, University Park, PA 16802, USA; M.W. Blair, International Center for Tropical Agriculture (CIAT), A.A. 6713, Cali, Colombia. Received 1 Dec. 2005. *Corresponding author (Fax: +1 814863 6139. E-mail: JPL4@psu.edu).

Published in Crop Sci. 46:1609-1621 (2006).

Crop Breeding \& Genetics

doi:10.2135/cropsci2005.12-0446

(c) Crop Science Society of America

677 S. Segoe Rd., Madison, WI 53711 USA
Plants display a variety of adaptations to low phosphorus availability, including changes in root morphology and architecture (Bonser et al., 1996; Fan et al., 2003; Lynch and Brown, 2001, 2005; Miller et al., 2003; Nielsen et al., 1998), increased production and secretion of root exudates (Jones, 1998; Yan et al., 1996), increased proliferation and elongation of root hairs (Bates and Lynch, 1996; Ma et al., 2001a), modification of carbon metabolism and alternative respiratory pathways (Rychter and Mikulska, 1990; Wanke et al., 1998), and enhanced expression of $\mathrm{P}_{\mathrm{i}}$ transporters (Ragothama, 2005). Selection for specific traits that improve phosphorus acquisition is preferable to yield trials where $\mathrm{G} \times \mathrm{E}$ interaction and a multiplicity of factors affecting yield have complicated the identification and selection for phosphorus efficiency in the past (Lynch and Beebe, 1995). Marker assisted selection would be an option to select for root traits that are difficult to evaluate phenotypically.

Phosphorus is relatively immobile in soil and its availability is typically greater in topsoil and declines substantially with depth (Lynch and Brown, 2001). Root architectural traits that enhance topsoil foraging such as shallower basal root growth angle (Bonser et al., 1996) or adventitious rooting (Lynch and Brown, 2001; Miller et al., 2003) may therefore enhance phosphorus acquisition in low phosphorus environments. In addition to exploring the topsoil, adventitious roots have lower metabolic cost than other root types (Miller et al., 2003), which is important since root costs are an important component of plant adaptation to low phosphorus environments (Lynch and Ho, 2005; Miller et al., 2003).

Genotypic variation in adventitious root formation has been observed in several crops including common bean (Miller et al., 2003), soybean [Glycine $\max$ (L.) Merr.: Bacanamwo and Purcell, 1999], Rumex ssp. (Visser et al., 1996), tomato (Lycopersicon esculentum L.: McNamara and Mitchell, 1990), and maize (Zea mays L.: Mano et al., 2005). In common bean phosphorus availability regulates adventitious rooting (Miller et al., 2003); however, there is a lack of information regarding the genetic basis for adventitious rooting and related traits.

In this study, we analyze QTL controlling variation for adventitious root traits in a RIL population developed from a cross between G2333 × G19839 and estimate

Abbreviations: QTL, quantitative trait locus (loci); RIL(s), recombinant inbred line(s); PCR, polymerase chain reaction; SSR, simple sequence repeat; RAPD, random amplified polymorphic DNA; SCAR, sequence characterized amplified region; STS, sequence tagged site; PAGE, polyacrylamide gel electrophoresis; CTAB, cetyl trimethyl ammonium bromide; LOD, logarithm of odd; CIM, composite interval mapping; MIM, multiple interval mapping; $\mathrm{cM}$, centimorgan; GxE, genotype by environment interaction; DAS, days after sowing; SRL, specific root length. 
the extent of phenotypic variation and heritability for adventitious root traits evaluated in field and greenhouse environments under contrasting phosphorus availability. This information should be important for the genetic enhancement of phosphorus efficient bean breeding lines.

\section{MATERIALS AND METHODS}

\section{Plant Material}

A total of $84 \mathrm{~F}_{5: 8}$ recombinant inbred lines (RIL) were developed at CIAT (International Center for Tropical Agriculture) by single seed descent from the cross G2333 × G19839 where G2333 ('Colorado de Teopisca') is a climbing, small redseeded Mexican landrace belonging to the Mesoamerican gene pool (Singh et al., 1991a) with a type IV growth habit (Singh, 1982); and G19839 is a large, yellow and red-mottled seeded Peruvian landrace with type III growth habit that belongs to the Andean gene pool (Singh et al., 1991a). These two landraces have shown the most contrasting phenotype for adventitious rooting among germplasm accessions previously evaluated in nutrient solution under greenhouse conditions.

\section{Field Experiment}

The field trial was conducted at the CIAT research farm in Darien, Colombia (03 $56^{\prime} \mathrm{N} ; 076^{\circ} 28^{\prime} \mathrm{W}$, elevation 1537 masl), during the rainy season from September to December 2001 with average yearly temperature of $20^{\circ} \mathrm{C}$ and annual rainfall $1288 \mathrm{~mm}$ (307 mm during the experiment). The soil at the field site is an Udand with native soil phosphorus of $2 \mathrm{ppm}$ [determined by Bray II extraction (Olsen and Sommers (1982)], pH 5.6 (soil:water 1:2), and $10.6 \%$ organic matter (dicromatesulfuric acid oxidation). Several years of fertility management to generate high- and low-phosphorus plots in this location resulted in plots having markedly different phosphorus availability with an average phosphorus concentration of $64.3 \mathrm{ppm}$ and $1.7 \mathrm{ppm}$ for high- and low-phosphorus plots, respectively. Before planting, the high-phosphorus plot received $45 \mathrm{~kg} \mathrm{ha}^{-1}$ phosphorus and the low-phosphorus plot received $7.5 \mathrm{~kg} \mathrm{ha}^{-1}$ phosphorus as triple super phosphate. To prevent zinc and boron deficiency typical of these soils, $600 \mathrm{~g} \mathrm{ha}^{-1}$ of $\mathrm{ZnSO}_{4}$ and $600 \mathrm{~g} \mathrm{ha}^{-1}$ of borax $\left[\mathrm{Na}_{2} \mathrm{~B}_{4} \mathrm{O}_{2}\left(\mathrm{H}_{2} \mathrm{O}\right)_{10}\right]$ were applied as a foliar feed every week after emergence for three consecutive weeks. Soil Nitrogen (molecular spectrometry after Sulfuric-salicylic digestion), $\mathrm{Mg}$ and $\mathrm{Mn}$ (atomic absorption spectrometry), and $\mathrm{B}$ (molecular spectrometry after hot water extraction) (Westerman, 1990) were checked after harvest and determined to be adequate. Phosphorus-free fungicides and pesticides were applied several times as needed. Seeds were sown at a depth of 7 to $8 \mathrm{~cm}$ and at $15 \mathrm{~d}$ after emergence plants were manually hilled with soil to slightly below the cotyledons.

Parental lines and their 84 RILs were manually sown in a randomized complete block design (RCBD) with a split plot arrangement of treatments where phosphorus levels were the main plots and RILs were the subplots. The experiment consisted of three replications over time to allow for efficient sampling of adventitious roots. Each experimental unit was a single 1-m-row plot sown with 15 seeds. One meter spacing between rows was used to accommodate both climbing and semiclimbing RILs. Total plant density was approximately 150000 plants ha ${ }^{-1}$. Controls of both parents were sown every fifth row as a single row as a covariate, if needed, for statistical analysis. Root systems were collected for two plants per row at $42 \mathrm{~d}$ after sowing (DAS), corresponding to the early flowering growth stage R6 (Singh, 1982) by carefully excavating the plants to reveal as many adventitious and basal roots as possible, and counting the number of adventitious roots emerging from the hypocotyls. Subsamples of both adventitious and basal roots were preserved in $25 \%$ ethanol and kept at $4^{\circ} \mathrm{C}$ until analyzed for root length. Shoots and remaining adventitious roots were oven dried at $60^{\circ} \mathrm{C}$ for 2 to $3 \mathrm{~d}$ for dry weight determination.

Adventitious and basal root subsamples were stained with $0.1 \mathrm{~g} \mathrm{~L}^{-1}$ neutral red dye (Sigma Chemical Co., St. Louis MO) for $24 \mathrm{~h}$ and mounted on a clear acrylic tray in shallow water for scanning and quantification of root length as well as other root parameters. A flatbed scanner (HP STD1600+, HewlettPackard) was used with a special lighting system (dual scan) to eliminate shadows. Scanned images were analyzed with WinRhizo Pro (Régent Instruments, Québec, Canada), adjusted as described by Bouma et al. (2000). Once root length was obtained, specific root length (SRL) was calculated as length per unit of root dry weight (meters per gram). SRL for adventitious root samples was used to estimate total adventitious root length. Prior experience in our lab has indicated that a representative subsample gives accurate estimates of whole or specific root type characteristics (Lynch and van Beem, 1993).

\section{Greenhouse Experiment}

The experiments were conducted in a temperature controlled greenhouse located at Pennsylvania State University, University Park, PA USA $\left(40^{\circ} 85^{\prime} \mathrm{N}, 77^{\circ} 82^{\prime} \mathrm{W}\right)$, during June to November 2000 and April to July 2001. The max/min temperatures were $28^{\circ} \mathrm{C} / 22^{\circ} \mathrm{C}$, photosynthetically active radiation (PAR) averaged 800 to $1000 \mu \mathrm{mol}$ photons $\mathrm{m}^{-2} \mathrm{~s}^{-1}$, and the average humidity was $60 \%$. Natural light was supplemented from 0800 to $2000 \mathrm{~h}$ with $110 \mu \mathrm{mol}$ photons $\mathrm{m}^{-2} \mathrm{~s}^{-1}$ from $400 \mathrm{~W}$ metal halide bulbs (Energy Technics, York, PA, USA). Seeds were surface-sterilized for 1 to $2 \mathrm{~min}$ in $10 \%(\mathrm{v} / \mathrm{v}) \mathrm{NaOCl}$, thoroughly rinsed with deionized water, mechanically scarified, and germinated in rolls of brown germination paper (Anchor Paper Co., St. Paul, MN, USA) placed upright in a $500 \mathrm{~mL}$ beakers containing $200 \mathrm{~mL}$ of half strength nutrient solution containing high or low phosphorus (see composition below). Seeds were allowed to germinate in darkness at $28^{\circ} \mathrm{C}$ for 4 to $5 \mathrm{~d}$. After $1 \mathrm{~d}$ of acclimatization to daylight, 6-d-old uniform seedlings were transplanted to plastic tanks (12 seedlings per container) filled with $30 \mathrm{~L}$ of aerated nutrient solution consisting of (in $\mu M$ ): $\mathrm{KNO}_{3}(1500), \mathrm{Ca}\left(\mathrm{NO}_{3}\right)_{2} \cdot \mathrm{H}_{2} \mathrm{O}(1200)$, $\mathrm{NH}_{4} \mathrm{NO}_{3}$ (400), $\mathrm{MgCl}_{2} \cdot 6 \mathrm{H}_{2} \mathrm{O}$ (25), Fe-Na-EDTA (5), $\mathrm{MgSO}_{4} .7 \mathrm{H}_{2} \mathrm{O}$ (500), $\mathrm{K}_{2} \mathrm{SO}_{4}$ (300), $\left(\mathrm{NH}_{4}\right)_{2} \mathrm{SO}_{4}$ (300), $\mathrm{MnSO}_{4} \cdot \mathrm{H}_{2} \mathrm{O}(1.5), \mathrm{ZnSO}_{4} \cdot 7 \mathrm{H}_{2} \mathrm{O}(1.5), \mathrm{CuSO}_{4} .5 \mathrm{H}_{2} \mathrm{O}(0.5)$, $\left(\mathrm{NH}_{4}\right)_{6} \mathrm{Mo}_{7} \mathrm{O}_{24} \cdot 4 \mathrm{H}_{2} \mathrm{O}(0.15)$, and $\mathrm{Na}_{2} \mathrm{~B}_{4} \mathrm{O}_{7} \cdot 10 \mathrm{H}_{2} \mathrm{O}$ (0.5). Phosphorus treatments were established by adding $1.5 \%(\mathrm{w}: \mathrm{v})$ solid-phase-buffered (alumina) phosphorus (Lynch et al., 1990) with two different desorption concentrations in the nutrient solution: $0.5-1 \mu \mathrm{M}$ phosphorus (low phosphorus) and $100 \mu M$ phosphorus (high phosphorus). In addition to the phosphorus desorbed from the alumina buffer, $1.0 \mu M$ and $500 \mu M$ of $\mathrm{KH}_{2} \mathrm{PO}_{4}$ solution for high- and low-phosphorus treatments, respectively, were added to the nutrient solution. In the low-phosphorus nutrient solution, $\mathrm{KH}_{2} \mathrm{PO}_{4}$ was replaced with $250 \mu M$ of $\mathrm{K}_{2} \mathrm{SO}_{4}$ to adjust for the difference in potassium between high- and low-phosphorus treatments. The $\mathrm{pH}$ of the nutrient solution was adjusted every other day to 5.8 with $\mathrm{KOH}$, and the nutrient solutions were replaced $7 \mathrm{~d}$ after transplanting. Seedlings were placed with the hypocotyls submerged approximately $7 \mathrm{~cm}$ into the nutrient solution to assure the maximum genotypic expression of adventitious rooting in all RILs, and their cotyledons removed $1 \mathrm{~d}$ after transplanting. 
The experimental design was a randomized complete block design, as in the field trial, but there were a total of five replicates staggered over time. Plants were harvested $14 \mathrm{~d}$ after germination. Shoots were dried at $60^{\circ} \mathrm{C}$ for 2 to $3 \mathrm{~d}$ for dry weight determination. Roots were separated into adventitious, basal, and taproots. A subsample of each type was preserved in $25 \%$ ethanol, kept at $4^{\circ} \mathrm{C}$, until analysis for root length. Remaining tissue was dried at $60^{\circ} \mathrm{C}$ for 2 to $3 \mathrm{~d}$ for biomass determination. Root length, dry weight, and specific root length were determined as described for the field experiment. In addition, adventitious root primordia were evaluated for the parents.

\section{DNA Isolation and Marker Analysis}

Etiolated leaf tissue of three to five seedlings was collected for each RIL and the total genomic DNA was isolated following the CTAB miniprep method as described by Afanador and Haley (1993). DNA concentrations were measured by a Hoefer fluorometer (Dynaquant 200, Hoefer Scientific Instruments, San Francisco, CA, USA) and they were diluted to $10 \mathrm{ng}$ $\mu \mathrm{L}^{-1}$ for further use in PCR reactions. Molecular markers used in the study included a total of 106 simple sequence repeat (SSR) or microsatellites (Blair et al., 2003; Gaitan-Solis et al., 2002; Yu et al., 2000); 34 random amplified polymorphic DNA (RAPD) primers (Operon Technologies Inc., Alameda, CA) 15 common bean disease resistance sequence characterized amplified region (SCAR) markers (http://www.ars.usda. gov/SP2UserFiles/person/3848/pdf/ScarTable 3.pdf/); and 3 sequence tagged site markers (STS) linked to seed coat color (McClean et al., 2002). In addition, the phaseolin marker was evaluated using a total extract of seed proteins (Singh et al., 1991b) and flower color was evaluated as a morphological marker. RAPD markers were named according to the primer used and the molecular weight of the band as a fraction of thousand $\mathrm{kb}$. PCR amplifications for the SSR markers were done in a PTC-200 thermocycler (MJ Research Inc., Watertown, MA) in a reaction mix volume of $12 \mu \mathrm{L}$ containing $20 \mathrm{ng}$ of bean genomic DNA, $0.1 \mu M$ of each of forward and reverse primers, $125 \mu M$ of each dNTP, 1 unit of Taq polymerase, and $10 \times$ PCR buffer. PCR amplification, PAGE electrophoresis, and silver staining detection conditions were as described in Blair et al. (2003). PCR products for the RILs were multiplexed with two to four loads per polyacrylamide gel.

The PCR amplifications for the RAPD, SCAR, and STS markers were conducted in a PTC-100 thermocycler (MJ Research Inc., Watertown, MA). The PCR reaction mix volume was $25 \mu \mathrm{L}$ containing $10 \mathrm{ng}$ of bean genomic DNA, $0.8 \mu M$ of primer, $200 \mu \mathrm{M}$ of each dNTP, 1 unit of Taq polymerase, and 10X PCR buffer with $10 \mathrm{~m} M$ of Tris- $\mathrm{HCl}(\mathrm{pH} 7.2)$, $50 \mathrm{~m} M$ of $\mathrm{KCl}$, and $2.5 \mathrm{mM}$ of $\mathrm{MgCl}_{2}$. Marker amplifications were standardized to 38 cycles at $91^{\circ} \mathrm{C}$ for $15 \mathrm{~s} ; 42^{\circ} \mathrm{C}$ annealing for $15 \mathrm{~s}$; and $72^{\circ} \mathrm{C}$ extension for $1 \mathrm{~min}$. The last cycle was followed by $5 \mathrm{~min}$. extension at $72^{\circ} \mathrm{C}$. A total of $5 \mu \mathrm{L}$ of PCR products were loaded onto $1.5 \%$ (w/v) agarose gels with ethidium bromide and run in horizontal electrophoresis chamber (Horizon 20-25 BRL Life Technologies Inc., Gaithersburg, $\mathrm{MD}, \mathrm{USA}$ ) at $240 \mathrm{~W}$ for $30 \mathrm{~min}$ in which $150 \mathrm{~mL}$ of TBE $0.5 \times$ buffer was added. PCR amplification products were visualized under UV light and photographed with a Polaroid GelCam DS-34 camera (Waltham, MA, USA).

\section{Phenotypic Data Analyses}

For both field and greenhouse experiments, statistical differences for main effects [phosphorus-treatment (main plot) and RILs (sub-plot)], and first-order interaction were ascer- tained with the generalized linear model (GLM) procedure in SAS, version 8.02 (SAS, 1985). Before analysis of variance (ANOVA) all variables were tested for normality among RILs using the UNIVARIATE procedure in SAS. Estimates of narrow-sense heritability $\left(h_{\mathrm{ns}}^{2}\right)$ for the RIL population were determined from variance components and the number of self crossing generations (Hallauer and Miranda Filho, 1988) using expected mean squares as follows:

$$
h_{\mathrm{ns}}^{2}=\sigma_{A}^{2} / \sigma_{G}^{2}
$$

where: $\sigma_{\mathrm{A}}^{2}=\sigma_{G}^{2} /(15 / 8) ; \sigma_{G}^{2}=$ genotypic variance $\left(\left[\mathrm{MS}_{\mathrm{RILs}}-\right.\right.$ $\left.\left.\mathrm{MS}_{\text {Error }}\right] / k\right)$; and $k=$ number of replications. The standard errors for the narrow-sense heritability $\left(h_{\mathrm{ns}}^{2}\right)$ values were calculated (After Knapp et al., 1985) as follows:

$$
\mathrm{SE}\left(\mathrm{h}_{\mathrm{ns}}^{2}\right)=\sqrt{2\left(1-h_{\mathrm{ns}}^{2}\right)^{2} \frac{1}{n_{1}+1}+\frac{1}{n_{2}+2}}
$$

where: $n_{1}=$ RILs' degrees of freedom; $n_{2}=$ error's degrees of freedom

Frequency distribution charts were made for all adventitious root traits with the number of classes derived from the formula $K=1+3.3 \times \log X$, where $X$ is the number of observations and the class intervals were obtained by dividing the $K$ value by the range of the variable. Pearson's correlations were calculated among phenotypic variables for all combinations of traits in each phosphorus treatment and across phosphorus treatments for each root trait. Additionally, to characterize the size-dependent variations between root and shoot biomass at harvest, root-shoot allometric coefficients $(K)$ were determined from a series of paired measurements of root and shoot dry weight (DW) by linear regression of the form:

$$
K=\left(\log _{10} R-\log _{10} b\right) / \log _{10} S
$$

where $R$ is root DW (mg), $S$ is shoot DW $(\mathrm{g}), b$ is a constant, and $K$ is the allometric coefficient (Hunt, 1990).

\section{Genotypic Data Analyses}

Linkage analysis was conducted using the software MAPMAKER/EXP 3.0 for Windows (Lander et al., 1987) set to the Kosambi mapping function. To create a framework map, a subset of markers with a LOD of 6.0 and a maximum distance of $20 \mathrm{cM}$ were identified and then used for the placement of additional markers based on the most-likely interval using the 'try' command. The best marker order of the linkage groups was determined using a minimum LOD of 4.0 with the 'compare' and 'ripple' commands. Linkage groups were named according to the core reference map (Freyre et al., 1998) based on microsatellite map locations in Blair et al. (2003).

QTL analysis was conducted with the resulting genetic map and the phenotypic means for each RIL using the computer software program QTL Cartographer version 2.0 for Windows (Basten et al., 2003). QTL for given adventitious root traits and their combined effects were identified with both Composite Interval Mapping (CIM) and Multiple Interval Mapping (MIM) features. Parameters for CIM and MIM analysis included a forward/backward regression with a window size of $10 \mathrm{cM}$, a walk speed of $1 \mathrm{cM}$ and probability thresholds of 0.05 each for the partial F-test for both marker inclusion and exclusion. The empirical thresholds for QTL detection with the CIM method were estimated using 1000 permutation tests as suggested by Churchill and Doerge (1994). Additivity estimates for each adventitious root trait were computed by the QTL Cartographer program at the peak of the LOD profile. 


\section{RESULTS}

\section{Phenotypic Variation}

Adventitious rooting traits in both field and greenhouse, under both phosphorus levels, were quantitative (Fig. 1). Normal distributions were evident for all traits, except for adventitious biomass and adventitious length under low phosphorus conditions in the field. These nonnormal variables were transformed with square root and the inverse of the square root transformations while all others were left untransformed. Transgressive segregation in both directions was also observed in almost all

\section{Number of adventitious roots}

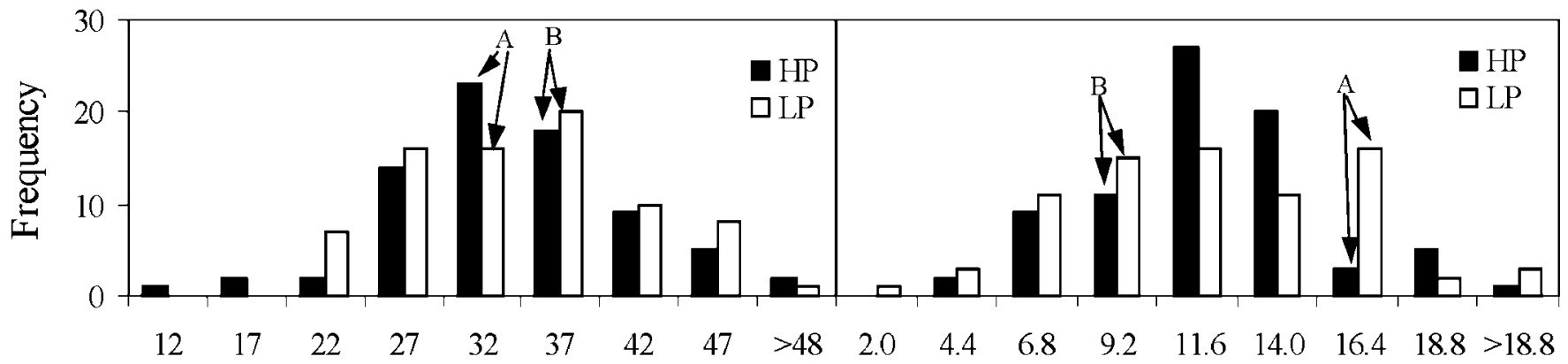

Adventitious root biomass (mg)

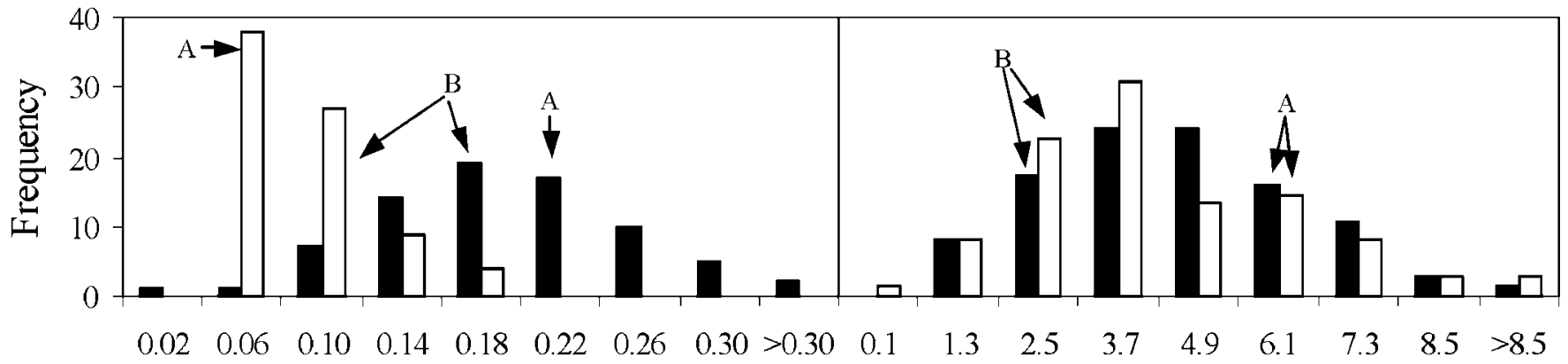

Adventitious root length (m)
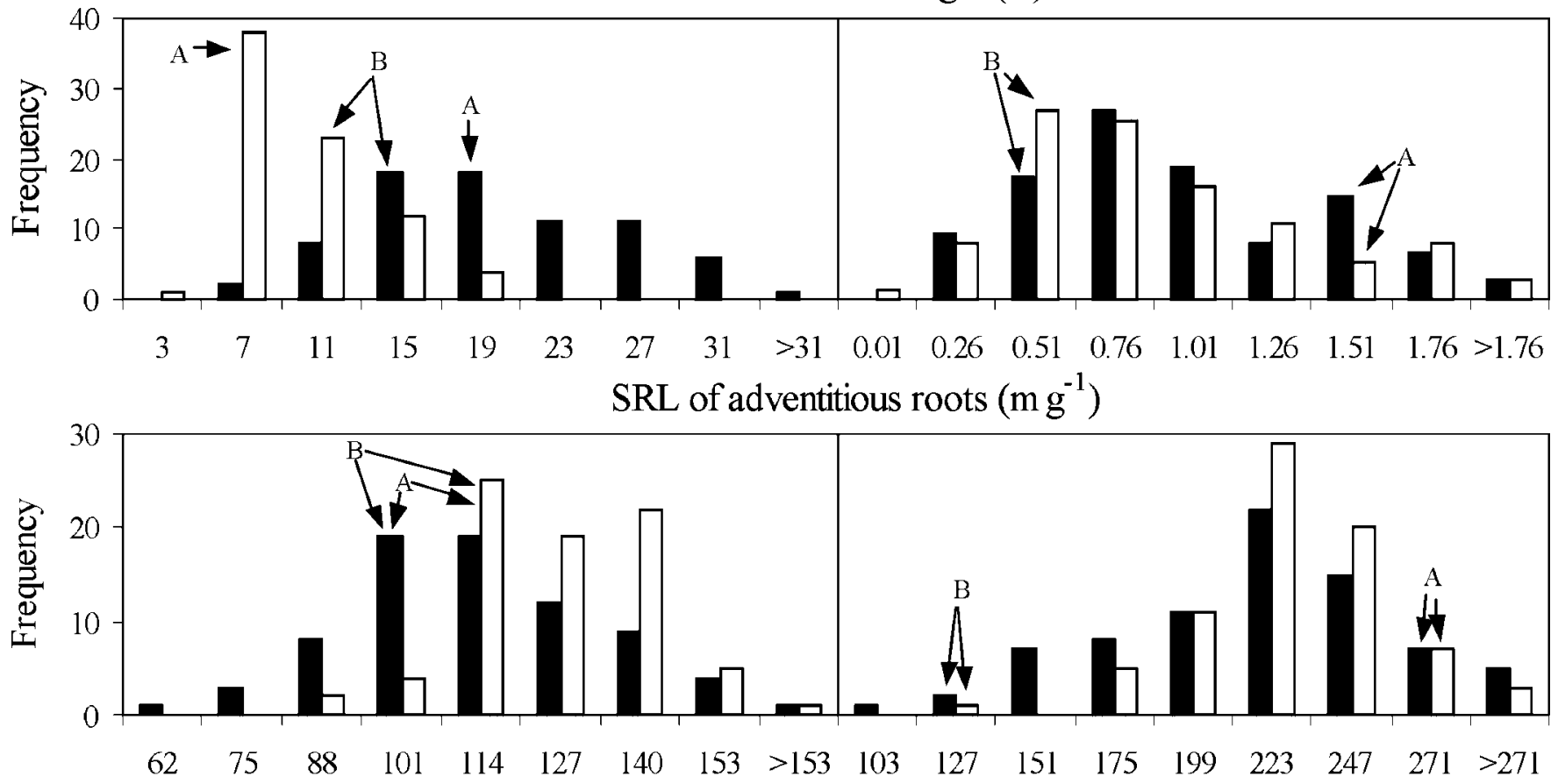

(a) Field

(b) Greenhouse

Fig. 1. Frequency distributions of 76 RILs and their parents 'G2333' (A) and 'G19839' (B) for four adventitious root traits under field (a) and greenhouse (b) conditions in high- and low-phosphorus environments. Arrows indicate frequency class for the parents. 
Table 1. Means for parents G2333 and G19839 and their RILs, ranges in RILs, and narrow-sense heritability (hns) of four adventitious root traits under field and greenhouse (GH) conditions in both high- (HP) and low- (LP) phosphorus environments. Mean of 4 (field) or 5 (greenhouse) replicates $\pm \mathrm{SE}$.

\begin{tabular}{|c|c|c|c|c|c|c|c|c|}
\hline \multirow[b]{2}{*}{ Adventitious root traits } & \multirow[b]{2}{*}{ P_level } & \multicolumn{3}{|c|}{ Parents } & \multicolumn{3}{|c|}{ RILs } & \multirow[b]{2}{*}{$h_{\mathrm{ns}}^{2}$} \\
\hline & & G19839 & G2333 & $\boldsymbol{P}_{\mathbf{P}}$ & Mean & Range & $\boldsymbol{P}_{\text {RIL }}$ & \\
\hline \multicolumn{9}{|l|}{ Number } \\
\hline \multirow[t]{2}{*}{ Field } & HP & $34.6 \pm 2.8$ & $29.8 \pm 1.5$ & ns & $31.8 \pm 0.7$ & $12.0-52.0$ & $* * *$ & $\mathbf{0 . 3 6} \pm \mathbf{0 . 1 3}$ \\
\hline & $\mathbf{L P}$ & $33.0 \pm 2.6$ & $31.8 \pm 3.1$ & ns & $32.1 \pm 0.7$ & $18.3-53.8$ & $* * *$ & $\mathbf{0 . 3 7} \pm \mathbf{0 . 1 2}$ \\
\hline \multirow[t]{2}{*}{ GH } & HP & $\mathbf{7 . 0} \pm \mathbf{2 . 0}$ & $14.1 \pm 1.9$ & $* * *$ & $\mathbf{1 1 . 0} \pm \mathbf{0 . 4}$ & 3.4-19.4 & $* * *$ & $\mathbf{0 . 2 6} \pm \mathbf{0 . 1 3}$ \\
\hline & $\mathbf{L P}$ & $7.8 \pm 2.7$ & $14.2 \pm 2.0$ & $*$ & $\mathbf{1 1 . 0} \pm \mathbf{0 . 4}$ & $2.0-21.4$ & $* * *$ & $\mathbf{0 . 3 1} \pm \mathbf{0 . 1 2}$ \\
\hline \multicolumn{9}{|l|}{ Biomass (mg) } \\
\hline \multirow{2}{*}{ Field } & HP & $153.1 \pm 17.4$ & $187.5 \pm 22.3$ & ns & $178.3 \pm 6.5$ & 22.3-306.9 & ns & $\mathbf{0 . 1 0} \pm \mathbf{0 . 1 8}$ \\
\hline & $\mathbf{L P}$ & $81.1 \pm 14.2$ & $60.6 \pm 9.2$ & ns & $72.2 \pm 2.8$ & $22.9-166.0$ & $* * *$ & $\mathbf{0 . 3 7} \pm \mathbf{0 . 1 2}$ \\
\hline \multirow[t]{2}{*}{ GH } & HP & $2.1 \pm 0.8$ & $5.4 \pm \mathbf{0 . 8}$ & $* *$ & $3.9 \pm 0.2$ & $0.4-10.9$ & $* * *$ & $0.34 \pm \mathbf{0 . 1 2}$ \\
\hline & $\mathbf{L P}$ & $1.7 \pm 0.6$ & $6.0 \pm 0.7$ & $* *$ & $3.6 \pm 0.2$ & $0.1-9.4$ & $* * *$ & $\mathbf{0 . 3 4} \pm \mathbf{0 . 1 2}$ \\
\hline \multicolumn{9}{|l|}{ Length (m) } \\
\hline \multirow[t]{2}{*}{ Field } & HP & $14.4 \pm 1.7$ & $15.9 \pm 1.5$ & ns & $18.4 \pm 0.7$ & 3.2-31.4 & + & $\mathbf{0 . 1 0} \pm \mathbf{0 . 1 8}$ \\
\hline & LP & $8.6 \pm 1.4$ & $6.9 \pm \mathbf{1 . 1}$ & ns & $8.4 \pm \mathbf{0 . 3}$ & 3.1-17.8 & $* * *$ & $\mathbf{0 . 3 4} \pm \mathbf{0 . 1 3}$ \\
\hline \multirow[t]{2}{*}{ GH } & HP & $\mathbf{0 . 4} \pm \mathbf{0 . 1}$ & $1.3 \pm \mathbf{0 . 2}$ & $* * *$ & $0.9 \pm 0.1$ & $0.1-2.7$ & $* * *$ & $\mathbf{0 . 3 5} \pm \mathbf{0 . 1 2}$ \\
\hline \multirow{2}{*}{\multicolumn{9}{|c|}{ Specific Root Length $\left(\mathrm{m} \mathrm{g}^{-1}\right)$}} \\
\hline & & & & & & & & \\
\hline \multirow[t]{2}{*}{ Field } & HP & $96.1 \pm 3.8$ & $92.0 \pm 8.9$ & ns & $\mathbf{1 0 7 . 5} \pm \mathbf{2 . 0}$ & 61.9-168.9 & $* * *$ & $0.28 \pm \mathbf{0 . 1 5}$ \\
\hline & LP & $110.0 \pm 6.6$ & $112.7 \pm 5.4$ & ns & $120.0 \pm 1.7$ & 86.9-152.9 & $*$ & $\mathbf{0 . 1 8} \pm \mathbf{0 . 1 6}$ \\
\hline \multirow[t]{2}{*}{ GH } & HP & $105.1 \pm 23.0$ & $275.7 \pm \mathbf{3 2 . 9}$ & $* * *$ & $205.1 \pm 3.8$ & 42.1-286.4 & $* * *$ & $\mathbf{0 . 5 1} \pm \mathbf{0 . 0 9}$ \\
\hline & LP & $113.9 \pm 26.9$ & $250.7 \pm \mathbf{1 2 . 9}$ & $* *$ & $212.3 \pm 3.7$ & 152.4-294.6 & $* * *$ & $\mathbf{0 . 2 5} \pm \mathbf{0 . 1 3}$ \\
\hline
\end{tabular}

${ }^{+}$Significant differences between the two parents $\left(P_{P}\right)$ or among RILs ( $\left.P_{R I L}\right)$ at $P=0.1$.

* Significant differences between the two parents $\left(\mathbf{P}_{\mathbf{P}}\right)$ or among $\mathrm{RILs}\left(\mathbf{P}_{\mathbf{R I L}}\right)$ at $P=0.05$.

** Significant differences between the two parents $\left(\mathbf{P}_{\mathbf{P}}\right)$ or among $\mathrm{RILs}\left(\mathbf{P}_{\mathbf{R I L}}\right)$ at $P=0.01$.

*** Significant differences between the two parents $\left(\mathbf{P}_{\mathbf{P}}\right)$ or among $\mathbf{R I L s}\left(\mathbf{P}_{\mathbf{R I L}}\right)$ at $\boldsymbol{P}=\mathbf{0 . 0 0 1}$.

adventitious root traits, but was more noticeable in the field where parents were intermediate than in the greenhouse where parents were located toward the ends of the population distribution. Indeed, although the differences between the parents were not statistically significant under field conditions in either phosphorus treatment, large and significant variation was observed among the RILs with the mean number of adventitious roots ranging from 12 to 53.8 , adventitious biomass from 22.3 to $306.9 \mathrm{mg}$, adventitious length from 3.1 to $31.4 \mathrm{~m}$, and specific root length (SRL) from 61.9 to $168.9 \mathrm{mg} \mathrm{m}^{-1}$ (Table 1, Fig. 1).

Under greenhouse conditions the parent G2333 produced as much as twice the number of adventitious roots as G19839 with almost no differences between phosphorus treatments (Table 1). However, when the number of adventitious root primordia (dedifferentiated cells of the stem parenchyma) was examined and added to the extended adventitious roots in both parents under high- and low-phosphorus conditions the total numbers of meristems were not significantly different between the parental lines (Fig. 2). Under greenhouse conditions the values for most of the other adventitious root traits for G2333 were two to five times higher than for G19839. We did not compare treatments across environments (field vs. greenhouse) because they were harvested at two different plant ages. The population means of most traits were between the parental values, except for adventitious root length under high-phosphorus field conditions and SRL in both phosphorus field treatments, where the population mean was higher than the highest parent value and the maximum value was almost twice the mean parental value (Table 1).

\section{Heritability and Correlations among Traits}

Narrow-sense heritability was medium-low to medium for almost all adventitious root traits, except for relatively low values for adventitious biomass and length in the field under high-phosphorus conditions $(0.10$ in both traits), and SRL in the field under low-phosphorus conditions (0.18) (Table 1). The highest heritability value was observed for SRL in high-phosphorus under greenhouse conditions $(0.51)$, followed by number and biomass of adventitious roots in the low-phosphorus field treatment (0.37). Medium-low heritabilities were observed for SRL in the low-phosphorus greenhouse $(0.25)$ and high-phosphorus in the field $(0.28)$ as well as for the number of adventitious roots in both highphosphorus (0.26) and low-phosphorus (0.31) under greenhouse conditions.

Phenotypic correlations among traits and across phosphorus treatments or environments are presented in Table 2. The correlations between phosphorus treatments, presented across the diagonal, were positive and

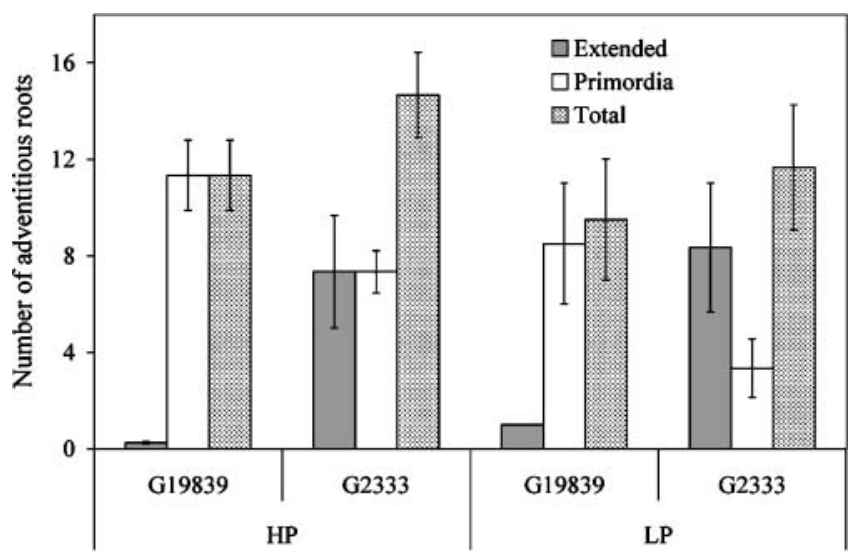

Fig. 2. Extended adventitious roots, adventitious root primordia, and total number of adventitious root meristems in the parental lines G2333 and G19839 under high- (HP) and low- (LP) phosphorus availability. 
Table 2. Phenotypic correlations among adventitious root traits and shoot biomass: number of adventitious (AdvNo), adventitious dry weight (AdvDW), adventitious length (Adv_L), adventitious specific root length (SRL_Adv), and shoot dry weight (ShDW).

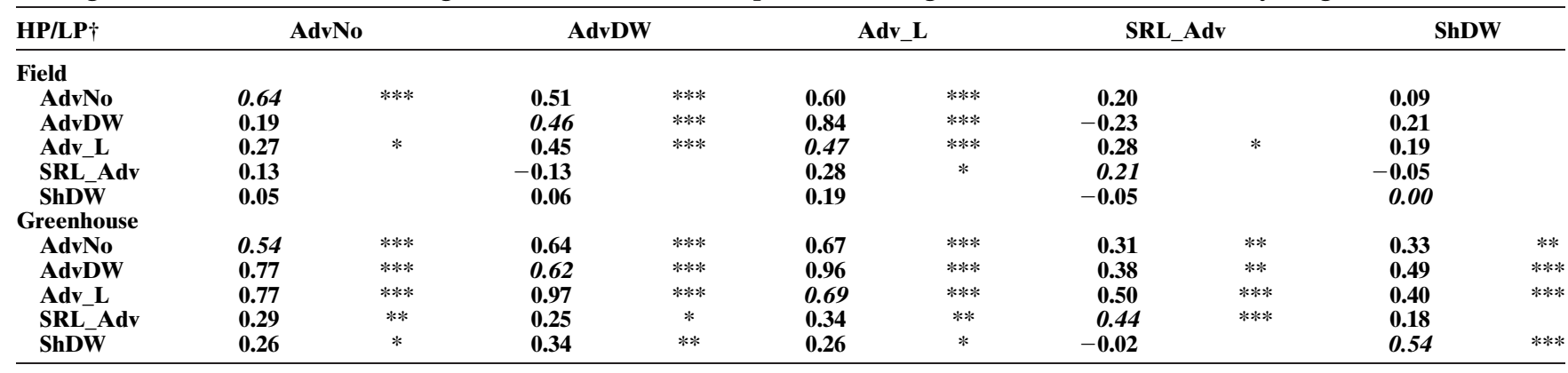

* Significant differences between the two parent at $P=0.05$.

** Significant differences between the two parents at $P=0.01$.

*** Significant differences between the two parents at $P=0.001$.

$\dagger$ For each environment, values below the diagonal represent correlations within the low-phosphorus treatments; values above the diagonal represent correlations within the high-phosphorus treatments; values on the diagonal (italics) correspond to across-phosphorus treatment correlations.

highly significant for all traits except for shoot biomass and adventitious SRL in the field. Few correlations between field and greenhouse environments were significant (data not shown), and these were primarily observed across phosphorus treatment, namely for number of adventitious root $(0.38, P<0.001)$, shoot dry weight $(0.23, P=0.05)$, and under low-phosphorus conditions for adventitious rooting vs. adventitious biomass $(0.23, P=0.05)$. All other correlations between field and greenhouse conditions were not significant. The highest correlation within environments was observed between adventitious length and adventitious biomass in both field and greenhouse high-phosphorus treatments and in the greenhouse low-phosphorus treatment $(0.84,0.96$, and 0.97 respectively). Yield per plant under low-phosphorus availability in the field was not correlated with adventitious root traits measured in the field or greenhouse (data not shown).

Biomass allocation patterns, as revealed by allometric analysis (Niklas, 1994), depended on root class. Allocation to taproots and basal roots was closely linked to overall shoot growth in the greenhouse, and was not affected by phosphorus availability as indicated by the relatively high coefficients of determinations for both high- and lowphosphorus treatments $\left(r^{2}=0.60\right.$ and $r^{2}=0.32$ respectively) and similar slope relationships (Fig. 3a). In contrast, allocation to adventitious roots varied substantially among RILs, as indicated by low coefficients of determination in the allometric analysis, in both field and greenhouse $\left(r^{2}=0.099\right.$ to 0.334$)$.

\section{Genetic Mapping and QTL Analysis}

Parental polymorphism for the G2333 × G19839 population was high with $72.6 \%$ of the microsatellite markers assayed polymorphic; while for RAPD primers and SCAR markers the polymorphism rates were $85.3 \%$ and $53.3 \%$, respectively. Overall the percentage of polymorphism between the two parents was $74.4 \%$ (119 out of 160 markers). A total of 167 polymorphic loci were obtained for mapping (80 SSRs, 74 RAPD, 8 SCAR, and 3 STS markers, in addition to one biochemical marker, the phaseolin locus, and one morphological marker for flower color). The majority of the SSR, SCAR, and
STS markers produced a single band; however, four SSR markers (BM181, BM188, BMd18, and BMd045) produced double banding-pattern; in these cases different bands were interpreted as separate loci.

A total of 149 of the 167 polymorphic markers evaluated in the entire mapping population could be assigned to the genetic map, which consisted of 11 linkage groups and a total cumulative length of $1175 \mathrm{cM}$. Average linkage group length was $106.81 \mathrm{cM}$ with an average of 13.5 markers per linkage group. Linkage groups were correlated with the genetic maps of Freyre et al. (1998) and Blair et al. (2003) by the mapping of syntenic markers. The least saturated linkage group (B1) had eight markers while the most saturated (B4) had 20. Only one microsatellite (BMd32) and 17 RAPD marker loci still remained unlinked from the final genetic map. The average distance between marker loci on all linkage groups was $7.89 \mathrm{cM}$, however their distribution was not uniform with some gaps remaining, particularly on linkage groups B1, B2, B3, B7, and B11. Several clusters of microsatellite markers were observed in various linkage groups but particularly on linkage groups B4, B7, and B10 and a lower coverage of marker loci was observed at the distal portion of linkage group B7 and at the top of linkage group B10. The biochemical marker phaseolin $(P h s)$ was mapped to the upper half of linkage group B7 which coincides with the location reported in other common bean maps (Adam-Blondon et al., 1994; Blair et al., 2003; Freyre et al., 1998; Nodari et al., 1993b; Vallejos and Chase, 1991; Vallejos et al., 1992). The morphological marker flower color $(V)$ was mapped to linkage group B6 also in agreement with previous studies (McClean et al., 2002; Nodari et al., 1993a).

\section{Quantitative Trait Loci Analysis}

A total of 20 QTL were identified for adventitious root-related traits (Table 3; Fig. 4) by means of composite interval mapping (CIM) and multiple interval mapping (MIM) analyses performed for each environment (field and greenhouse) and for each phosphorus treatment level (high- and low-phosphorus). Significant QTL were detected in linkage groups B2, B4, B6, B7, $\mathrm{B} 8, \mathrm{~B} 9, \mathrm{~B} 10$, and $\mathrm{B} 11$, and the phenotypic variation 
(a) Nutrient solution

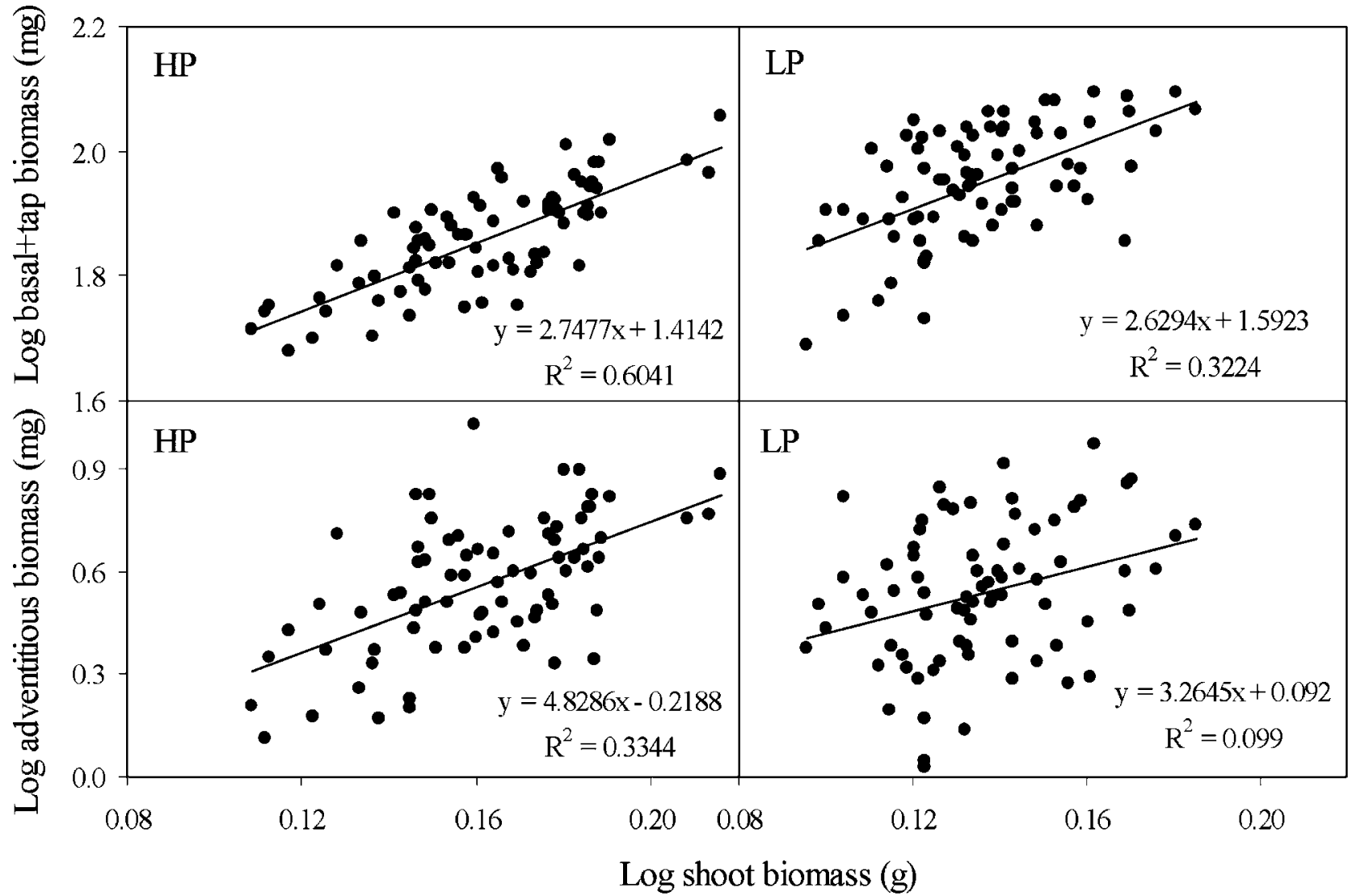

(b) Field

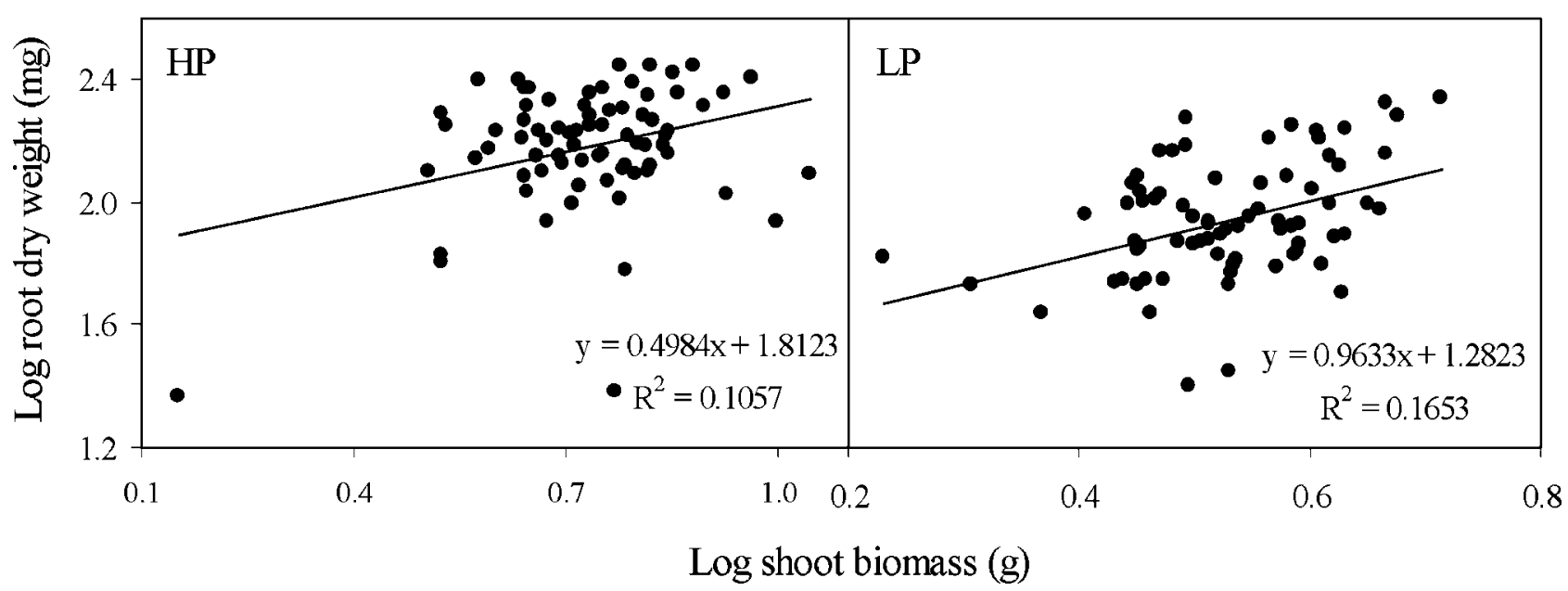

Fig. 3. Allometric relationships between the root type biomass (log scale) and shoot biomass (log scale) of 76 RILs from G2333 $\times$ G19839 grown under high- (HP) and low- (LP) phosphorus availability measured at 2 wk after germination in nutrient solution (a) and 6 wk after planting in the field (b).

explained by the individual QTL for adventitious root traits ranged from 11 to $36 \%$. Among the QTL, 15 were observed under high-phosphorus conditions (10 in the field and 5 in the greenhouse), while five were detected under low-phosphorus conditions ( 3 in the field and 2 in the greenhouse).

Three QTL for the number of adventitious roots in the field were identified on linkage groups B2 (under low phosphorus), B7 (high phosphorus), and B9 (high and low phosphorus). The QTL on linkage groups B7 and B9 together accounted for 33\% of the total phenotypic variation for this trait in high phosphorus; while QTL on linkage groups B2 and B9 explained up to $61 \%$ of the observed variation for the same trait in low phosphorus. Three QTL for adventitious root biomass under high-phosphorus field conditions were detected in the 
Table 3. Putative QTL for adventitious root traits under high- and low-phosphorus availability in the field (F) and greenhouse (G) conditions.

\begin{tabular}{|c|c|c|c|c|c|c|c|}
\hline Adventitious Traits & QTL name $\dagger$ & Linkage group & Nearest marker locus & LOD $\div$ & $\S R_{\text {CIM }}^{2}$ & II $R_{\text {МІМ }}^{2}$ & Additivity\# \\
\hline \multicolumn{8}{|l|}{ High P } \\
\hline \multirow{3}{*}{ Number (F) } & HPAdvNoF.1 & B7 & V100.29 & 3.68 & 0.14 & 0.12 & $-\mathbf{3 . 5 3}$ \\
\hline & HPAdvNoF.2 & B9 & P070.45 & 4.21 & 0.20 & 0.21 & 3.67 \\
\hline & & & Total $+\dagger$ & 2.74 & & 0.33 & \\
\hline \multirow[t]{4}{*}{ Biomass (F) } & HPAdvDWF.1 & B2 & P101.6 & 3.95 & 0.18 & 0.10 & -2.66 \\
\hline & HPAdvDWF.2 & B6 & P010.6 & 4.55 & 0.24 & 0.16 & -2.99 \\
\hline & HPAdvDWF.3 & B9 & M130.34 & 4.47 & 0.23 & 0.30 & 3.14 \\
\hline & & & Total & 5.40 & & 0.55 & \\
\hline Biomass (G) & HPAdvDWGH.1 & B8 & W090.36 & 4.02 & 0.18 & & 0.93 \\
\hline \multirow[t]{4}{*}{ Length (F) } & HPAdv_LF.1 & B2 & P101.6 & 3.66 & 0.18 & 0.14 & $-\mathbf{2 . 8 8}$ \\
\hline & HPAdv_LF.2 & B9 & M130.34 & 5.55 & 0.25 & 0.33 & 3.63 \\
\hline & HPAdv_LF.3 & B11 & PV-ag001 & 3.74 & 0.15 & 0.10 & 2.96 \\
\hline & & & Total & 4.83 & & 0.58 & \\
\hline Length (G) & HPAdv_LGH.1 & B8 & W090.36 & 4.38 & 0.18 & & 1.20 \\
\hline \multirow[t]{3}{*}{ SRL (F) } & HPSRL_AdvF.1 & B2 & Q171.7 & 3.59 & 0.15 & 0.07 & 9.45 \\
\hline & HPSRL_AdvF.2 & B7 & Phs & 3.30 & 0.18 & 0.04 & 9.44 \\
\hline & & & Total & 1.27 & & 0.19 & \\
\hline \multirow[t]{4}{*}{ SRL (G) } & HPSRL_AdvGH.1 & B6 & U190.35 & 3.24 & 0.11 & 0.14 & 16.44 \\
\hline & HPSRL_AdvGH.2 & B7 & BM185 & 3.20 & 0.11 & 0.12 & 15.35 \\
\hline & HPSRL_AdvGH.3 & B10 & M090.18 & 3.32 & 0.11 & 0.17 & 18.67 \\
\hline & & & Total & 3.96 & & 0.39 & \\
\hline \multicolumn{8}{|l|}{ Low $P$} \\
\hline \multirow[t]{3}{*}{ Number (F) } & LPAdvNoF.1 & B2 & P101.6 & 3.37 & 0.13 & 0.10 & -2.86 \\
\hline & LPAdvNoF.2 & B9 & P070.45 & 6.63 & 0.36 & 0.49 & 4.84 \\
\hline & & & Total & 4.41 & & 0.61 & \\
\hline SRL (F) & LPSRL_AdvF.1 & B2 & ВM142 & 5.14 & 0.25 & & -8.48 \\
\hline \multirow[t]{3}{*}{ SRL (G) } & LPSRL_AdvGH.1 & B4 & BMd027 & 5.65 & 0.23 & 0.16 & 14.25 \\
\hline & LPSRL_AdvGH.2 & B8 & BM153 & 4.09 & 0.18 & 0.15 & 13.35 \\
\hline & & & Total & 3.18 & & 0.31 & \\
\hline
\end{tabular}

$\dagger$ HP and LP in front of the abbreviation QTL name means high phosphorus and low phosphorus, respectively. For abbreviation descriptions refer to Table 2. $\$$ Maximum Log10 likelihood peak.

§ Proportion of the phenotypic variance explained by QTL at test site using CIM.

II Proportion of the phenotypic variance explained by all significant QTL using MIM.

\# Effects of substituting a single allele from one parent to another. Positive values indicate that allelic contribution is from G2333 and negative from G19839.

$\dagger \dagger$ Maximum LOD and the amount of phenotype variation simultaneously explained by all markers identified for a trait and determined by multiple QTL model.

same regions of linkage groups $\mathrm{B} 2$ and $\mathrm{B} 9$ as well as on linkage group B6. Together the three QTL explained $59 \%$ of the variation for adventitious root biomass and individually from 18 to $24 \%$. In the greenhouse, one QTL for adventitious root biomass was identified on linkage group B8 which accounted for $18 \%$ of the observed variability. For adventitious root length, three QTL were identified in the field environment and these were located on linkage groups B2, B9, and B11, together explaining $58 \%$ of the variation for the trait. Of the three QTL mapped for adventitious root length in high phosphorus, those on linkage groups B2 and B9 coincided in location with the QTL mentioned above for adventitious root biomass in high phosphorus as well as for the number of adventitious roots under high and low phosphorus. Only one QTL for adventitious root length was detected in the greenhouse under high-phosphorus conditions, which was located on linkage group B8, at the same position as the adventitious root biomass QTL identified for the greenhouse. This QTL accounted for $18 \%$ of observed phenotypic variation.

For specific root length (SRL) measured on adventitious roots grown under high-phosphorus conditions, QTL were identified for the field experiment on linkage groups B2 and B7 and for the greenhouse experiment on linkage groups B6, B7, and B10. These QTL accounted for $19 \%$ to $39 \%$ of the total variation for the traits. For adventitious SRL under low-phosphorus conditions in the field, only one QTL was detected in linkage group B2 and this explained $25 \%$ of the observed variation.
Finally, two QTL on linkage groups B4 and B8 were identified for SRL under greenhouse conditions, and together accounted for $31 \%$ of the variation observed. The biochemical marker phaseolin $(P h s)$ on linkage group B7 was significantly associated with a QTL for SRL of adventitious roots under high-phosphorus conditions and this QTL explained 18\% of the variation for this trait.

The positive alleles for all QTL detected on linkage groups B4, B8, B9, B10, and B11 were inherited from the maternal line $\mathrm{G} 2333$, while the positive alleles for the QTL located in linkage group B2 were inherited from the paternal line G19839, with the exception of the QTL for SRL of adventitious roots in the field under high-phosphorus conditions. The QTL for adventitious rooting under high- and low-phosphorus conditions detected on linkage group B9 near markers P070.45 and M130.34 had positive alleles that were inherited from G2333, while the other QTL identified on linkage groups B6 and B7 had positive alleles inherited from both parents.

\section{DISCUSSION}

Significant quantitative variation was observed in the G2333 $\times$ g19839 population used in this study not only for the number of adventitious roots formed but also for other adventitious root traits under sufficient and limited phosphorus availability in both field and greenhouse conditions. Quantitative variation for other root 

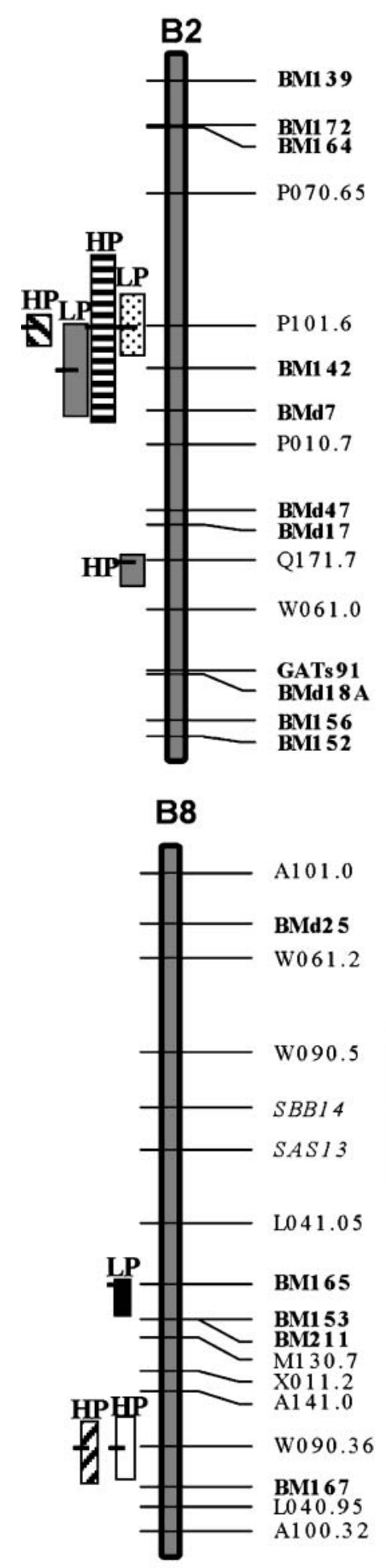
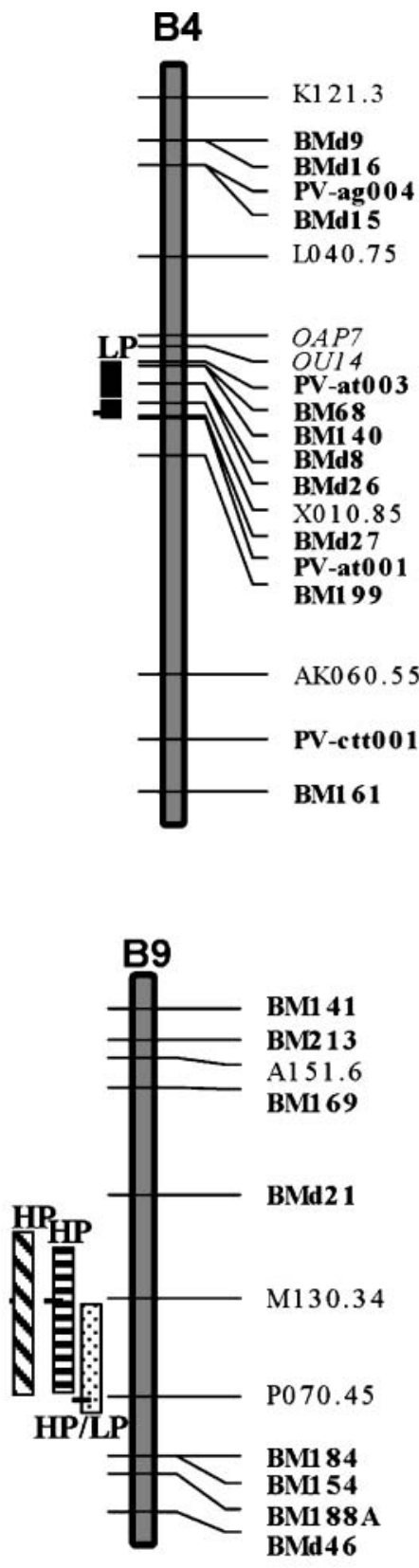
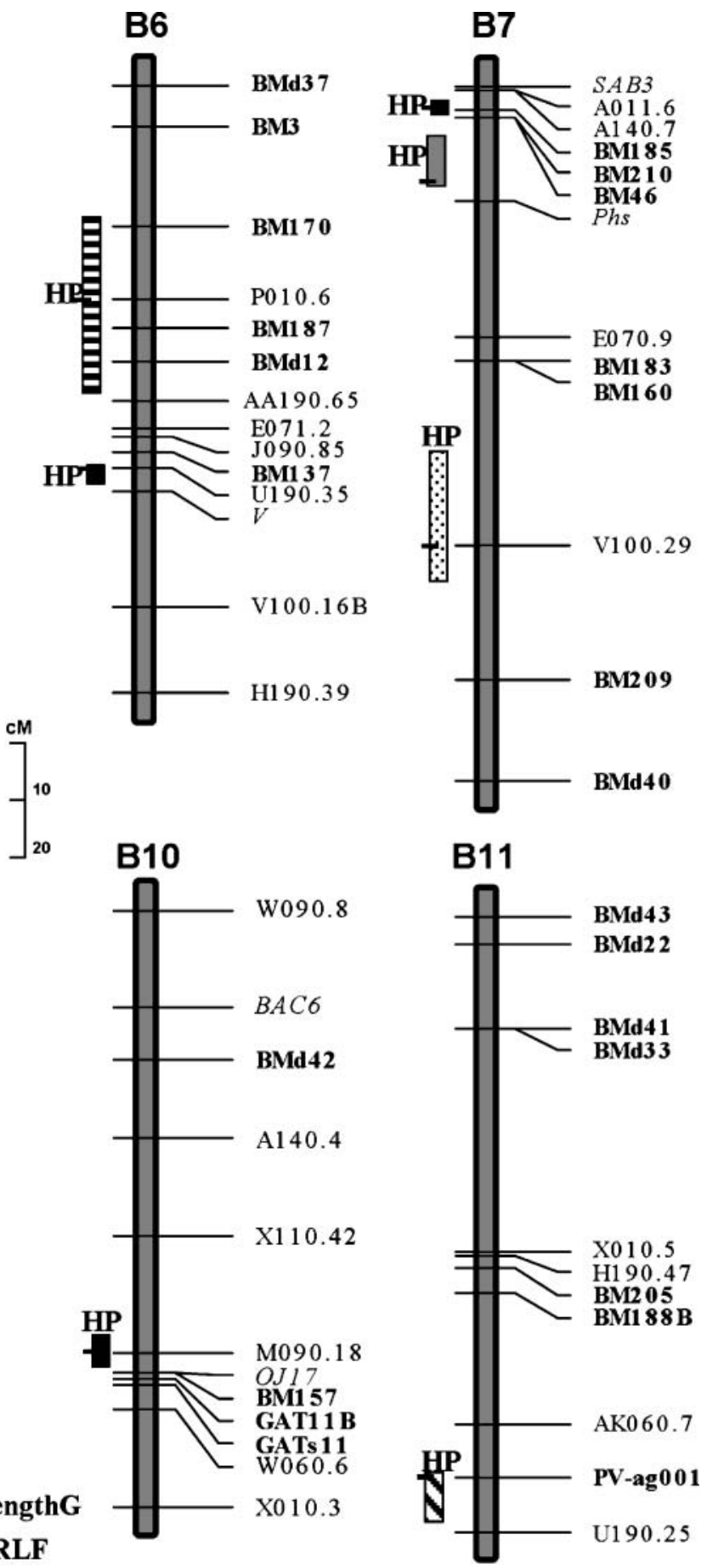

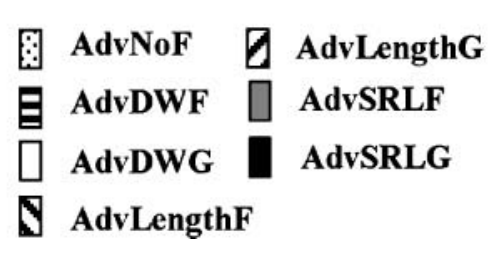

Fig. 4. Molecular markers and map location of putative QTL for several adventitious root traits in G2333/G19839 RIL population under high- (HP) and low-phosphorus (LP) conditions in the field (F) and greenhouse (G). Horizontal ticks perpendicular to the QTL bar indicate peak LOD location. For trait meanings, refer to Table 2.

traits, such as root hair length and density and basal root shallowness have also been reported in other RIL populations of common bean (Liao et al., 2004; Yan et al., 2004), maize (Mano et al., 2005; Zhu et al., 2005a, 2005b), and rice (Oryza sativa, Kamoshita et al., 2002; Price and Tomos, 1997). Although there were no signif- icant differences between the parents for adventitious rooting in the field, transgressive segregation in both directions was observed for all four traits evaluated (adventitious root number, biomass, length, and SRL), indicating that neither parent carried all positive or negative alleles for these traits. The parents were strongly 
contrasting for adventitious root traits in the greenhouse, and less transgressive segregation was observed in this environment compared to the field. Correlations between seed size and root trait values in the greenhouse in both phosphorus environments were very low and statistically not significant (data not shown), so we do not expect any confounding effect of seed size in our results.

One possible explanation for the differences between the field and greenhouse results is that the nutrient solution experiments in the greenhouse were harvested at $2 \mathrm{wk}$ after germination, while the field experiment was harvested 6 wk after planting. At this later stage G19839 had an equivalent number of adventitious roots, perhaps based on the preformed or induced adventitious root primordia which were present at the earlier stage but had not grown into adventitious roots in this line compared to G2333 (Fig. 2). This is consistent with the observation that the parents had the same number of meristems (counting extended root and adventitious root primordia) at $12 \mathrm{~d}$ in nutrient solution, but that G19839 had fewer extended adventitious roots than G2333. The field environment may also have presented other environmental variables and stresses that could have reduced the phenotypic difference between the parents. Lack of correlation between adventitious root traits and yield per plant under low phosphorus in the field could have been caused by the uncertainty associated with yield estimates from small plots in a single location and season. This lack of correlation is indirect support for our finding that adventitious rooting is not controlled by simple allometry with plant size.

Narrow-sense heritability values for almost all adventitious root traits evaluated were observed to be mediumlow to medium, reflecting polygenic control of the traits evaluated. However, it is interesting that almost all heritability values were higher in low-phosphorus than in high-phosphorus conditions in both field and greenhouse environments, and also slightly higher than for other root traits in common bean (Yan et al., 2004) or maize (Zhu et al., 2005a), suggesting that selection under low phosphorus would be more effective than selection under high phosphorus, and that adventitious root traits would be useful targets for bean breeding programs interested in improving phosphorus acquisition.

We observed few significant correlations between field and greenhouse experiments for adventitious root traits. However, the significant correlation across phosphorus treatments within field or greenhouse experiments (diagonal in Table 3) and between the number of adventitious roots in the field and greenhouse under low phosphorus $(r=0.38$ at $p \leq 0.001)$, independent of plant age (6-wk-old vs. 2-weeks-old), might indicate that greenhouse studies would be appropriate for screening a large number of accessions, or segregating populations for adventitious rooting. Unlike greenhouse conditions where almost all adventitious root traits had statistically significant correlations between high- and low-phosphorus treatments, amongst each other and between adventitious root traits and shoot biomass, under field conditions few significant correlations among ad- ventitious root traits or between adventitious root traits and shoot biomass were identified. The lack of correlation between adventitious root traits and shoot biomass in the field probably reflects the significant effect of other uncontrolled environmental factors in the expression of the traits under evaluation that are less prone to occur in more controlled environments. The allometric coefficient for basal plus taproot and shoot biomass was significant and not altered by phosphorus concentration. This suggests that taproots and basal roots maintain their proportionality to the shoot at low-phosphorus availability and that little genotypic variation should be expected under low-phosphorus conditions for these root classes. In contrast, the weak allometric relationship between adventitious root biomass and shoot biomass under low-phosphorus conditions indicated that allocation to adventitious roots varied substantially among RILs. If adventitious roots in the topsoil are advantageous for acquiring phosphorus under limited phosphorus availability, as suggested by Lynch and Brown (2001), this weak allometric relationship would facilitate the selection of efficient lines with high adventitious rooting in the field.

In addition to the trait analysis described above, we developed a new, primarily SSR-based linkage map for the G2333 × G19839 population for this study which builds on previous molecular linkage maps based on RFLP, RAPD, and/or AFLP markers (Freyre et al., 1998; Nodari et al., 1993a; Vallejos et al., 1992). Along with the DOR364 × G19833 map developed by Blair et al. (2003), our linkage map represents one of the most dense microsatellite-based molecular marker maps to date in common bean, containing a total of 79 microsatellites loci integrated with 70 additional RAPD, SCAR, and STS loci as well as the genes $P h s$ and $V$. Distribution of the microsatellite markers was generally random, however certain linkage groups (e.g., B4) were more heavily populated with this class of markers than others (e.g., B10). In addition, clustering of microsatellite loci occurred on linkage groups B3, B4, B7, and B10, results that agree with those of Blair et al. (2003). In general, alignment of this new map with other SSR-based maps will provide the opportunity for increasing marker density in selected genomic regions and comparative mapping of QTL observed in this study with other QTL related to phosphorus acquisition efficiency observed previously by our group (Liao et al., 2004; Yan et al., 2004). In this regard, we were able to detect 20 new QTL for root characteristics related to low-phosphorus adaptation specifically for adventitious rooting and other adventitious root-related traits under high- and low-phosphorus conditions in the field and greenhouse. They were located mainly in linkage groups B2 and B9 but also in linkage groups B4, $\mathrm{B} 6, \mathrm{~B} 8, \mathrm{~B} 10$, and B11. QTL associated with root morphology and related abiotic stress tolerances have been identified in several important agriculture crops including rice (Kamoshita et al., 2002; ZiChao et al., 2005), maize (Mano et al., 2005; Tuberosa et al., 2002; Zhu et al., 2005a, 2005b), and soybean (HongLin et al., 2004).

In the present study, we identified almost no overlap in the location of QTL detected for adventitious root 
traits between field and greenhouse conditions, with the exception of two QTL for SRL of adventitious roots under high-phosphorus conditions for each growth environment that were relatively close to each other on the top of linkage group B7. However, within growth environments, and particularly under field conditions, we identified coincidences in the location and direction of the genetic effects of QTL for the number, biomass, and length of adventitious roots in each phosphorus treatment as well as for the number of adventitious roots between high- and low-phosphorus environments on linkage groups B2 and B9, which could explain the high and significant correlations observed between these traits. Due to the co-location and matching sign of the corresponding additive effects, significant correlation between adventitious root traits could be attributed either to allometric associations or pleiotropic effects rather than tightly linked genes. Differences in QTL observed across the two environments might have differed due to differences in the age of the plants sampled or in the contrasting spatial distribution of phosphorus in soil vs. nutrient solution.

The combination of QTL identified for each root trait explained from 19 to $58 \%$ of the total phenotypic variation for the traits under high phosphorus in the field. Significantly, the combination of two QTL for number of adventitious roots under low phosphorus in the field on linkage group B9 explained $61 \%$ of total phenotypic variation, while one QTL for this trait explained alone as much as $36 \%$ of observed phenotypic variation and had the highest LOD value of all the QTL detected (6.63). This highly significant major QTL might be used along with some other major QTL reported for other root traits in common bean, such as total root hair length for tap root (Yan et al., 2004) and proportion of shallow basal root length and phosphorus uptake already detected in linkage group B9, as targets for a markerassisted selection program to incorporate multiple mechanisms of phosphorus acquisition efficiency in common bean. This QTL should be confirmed in at least two more environments and/or other mapping populations to be used further. While the positive alleles for most of the QTL were derived from the maternal parent G2333, the paternal line G19839 also contributed some beneficial alleles for the adventitious root traits, particularly for those QTL identified in linkage group B2. In common bean and maize, Liao et al. (2004), Yan et al. (2004), and Zhu et al. (2005a, 2005b) have also reported both parents contributing to the phenotypic expression of the root traits evaluated.

Giving the potential utility of adventitious rooting in low-phosphorus (Lynch and Brown, 2001; Miller et al., 2003) or hypoxic (Bacanamwo and Purcell, 1999; Mano et al., 2005; Visser et al., 1996) environments, the identification of QTL linked with adventitious rooting has implications for plant breeding. Since phenotypic selection for adventitious root traits is laborious, the use of markers linked to reliable QTL for specific adventitious root traits would be useful. In addition, adventitious root QTL could be combined with QTL for other traits such as acid exudation, root hair density, and basal root gravitropism which have been previously identified to be important for phosphorus acquisition efficiency for common bean (Liao et al., 2004; Yan et al., 2004). In other crops, similar molecular approaches have been used to dissect multiple root traits such as root hair, lateral root branching, and adventitious root formation in maize (Mano et al., 2005; Tuberosa et al., 2002; Zhu et al., 2005a, 2005b), or root depth and morphology in rice (Kamoshita et al., 2002; Price et al., 2002) and some breeding efforts for root traits are underway. Combining QTL for multiple root traits is desirable considering substantial synergism among root traits for phosphorus acquisition (Ma et al., 2001b), as well as root tradeoffs between water and phosphorus acquisition (Ho et al., 2005).

\section{ACKNOWLEDGMENTS}

We thank Oscar Checa and Hector Fabio Buendia for assistance with lab analysis, Dr. Stephen Beebe for assistance with population development, and Agobardo Hoyos and Yercil Viera for assistance with field work. This research was supported by USDA/NRI grant 99-35100-7596 to JPL and Kathleen M. Brown, Bean/Cowpea CRSP funding to JPL, and CIAT core funding to MWB.

\section{REFERENCES}

Adam-Blondon, A.F., M. Sévignac, H. Bannerot, and M. Dron. 1994 SCAR, RAPD and RFLP markers linked to a dominant gene (Are) conferring resistance to anthracnose in common bean. Theor. Appl. Genet. 88:865-870.

Afanador, L., and S.D. Haley. 1993. Adoption of a mini-prep DNA extraction method for RAPD marker analysis in common bean. Annu. Rpt. Bean Improv. Coop. 35:11.

Bacanamwo, M., and L.C. Purcell. 1999. Soybean root morphological and anatomical traits associated with acclimation to flooding. Crop Sci. 39:143-149.

Basten, C.J., S. Wang, P. Gaffney, and Z.B. Zeng. 2003. Windows QTL Cartographer, Version 2.0 Statistical Genetics, North Carolina State University, Raleigh, NC.

Bates, T.R., and J.P. Lynch. 1996. Stimulation of root hair elongation in Arabidopsis thaliana by low phosphorus availability. Plant Cell Environ. 19:529-538.

Beebe, S., J. Lynch, N. Galwey, J. Tohme, and I. Ochoa. 1997. A geographical approach to identify phosphorus-efficient genotypes among landraces and wild ancestors of common bean. Euphytica 95:325-336.

Blair, M.W., F. Pedraza, H.F. Buendia, E. Gaitan-Solis, S.E. Beebe, P. Gepts, and J. Tohme. 2003. Development of a genome-wide anchored microsatellite map for common bean (Phaseolus vulgaris L.). Theor. Appl. Genet. 107:1362-1374.

Bonser, A.M., J. Lynch, and S. Snapp. 1996. Effect of phosphorus deficiency on growth angle of basal roots in Phaseolus vulgaris. New Phytol. 132:281-288.

Bouma, T.J., K.L. Nielsen, and B. Koutstaal. 2000. Sample preparation and scanning protocol for computerized analysis of root length and diameter. Plant Soil 218:185-196.

Broughton, W.J., G. Hernandez, M. Blair, S. Beebe, P. Gepts, and J. Vanderleyden. 2003. Beans (Phaseolus spp.)-model food legumes. Plant Soil 252:55-128.

Churchill, G.A., and R.W. Doerge. 1994. Empirical threshold values for quantitative trait mapping. Genetics 138:963-971.

CIAT. 2001. CIAT Annual report 2000. CIAT (Centro Internacional de Agricultura Tropical), Cali, Colombia.

Fan, M.S., J.M. Zhu, C. Richards, K.M. Brown, and J.P. Lynch. 2003. Physiological roles for aerenchyma in phosphorus-stressed roots. Funct. Plant Biol. 30:493-506.

Freyre, R., P.W. Skroch, V. Geffroy, A.F. Adam-Blondon, A. 
Shirmohamadali, W.C. Johnson, V. Llaca, R.O. Nodari, P.A. Pereira, S.M. Tsai, J. Tohme, M. Dron, J. Nienhuis, C.E. Vallejos, and P. Gepts. 1998. Towards an integrated linkage map of common bean. 4. Development of a core linkage map and alignment of RFLP maps. Theor. Appl. Genet. 97:847-856.

Gaitan-Solis, E., M.C. Duque, K.J. Edwards, and J. Tohme. 2002. Microsatellite repeats in common bean (Phaseolus vulgaris): Isolation, characterization, and cross-species amplification in Phaseolus ssp. Crop Sci. 42:2128-2136.

Gerloff, G.C., and W.H. Gabelman. 1983. Genetic basis of inorganic plant nutrition. In Encyclopedia of Plant Physiology.A. Läuchli and R. L. Bieleski (ed.) p. 453-480. Springer-Verlag, Berlin.

Graham, P.H., and P. Ranalli. 1997. Common bean (Phaseolus vulgaris L). Field Crops Res. 53:131-146.

Hallauer, A.R., and J.B. Miranda Filho. 1988. Quantitative genetics in maize breeding. 2nd ed. Ames, Iowa State Univ. Press, 1988.

Ho, M.D., J.C. Rosas, K.M. Brown, and J.P. Lynch. 2005. Root architectural tradeoffs for water and phosphorus acquisition. Funct. Plant Biol. 32:737-748.

HongLin, W., Y. DeYue, W. YongJun, C. Shou Yi, and G. JunYi. 2004. Mapping QTL of soybean root weight with RIL population NJRIKY. Hereditas (Beijing) 26:333-336.

Hunt, R. 1990. Basic growth analysis: Plant growth analysis for beginners. First ed. Unwin Hyman Ltd, London.

Jones, D.L. 1998. Organic acids in the rhizosphere - a critical review. Plant Soil 205:25-44.

Kamoshita, A., L.J. Wade, M.L. Ali, M.S. Pathan, J. Zhang, S. Sarkarung, and H.T. Nguyen. 2002. Mapping QTL for root morphology of a rice population adapted to rainfed lowland conditions. Theor. Appl. Genet. 104:880-893.

Knapp, S.J., W.W. Stroup, and W.M. Ross. 1985. Exact confidence intervals for heritability on a progeny mean basis. Crop Sci. 25:192-194.

Lander, E.S., P. Green, J. Abrahamson, A. Barlow, M.J. Daly, S.E. Lincoln, and L. Newburg. 1987. MAPMAKER: An interactive computer package for constructing primary genetic linkage maps of experimental and natural populations. Genomics 1:174-181.

Liao, H., X.L. Yan, G. Rubio, S.E. Beebe, M.W. Blair, and J.P. Lynch. 2004. Genetic mapping of basal root gravitropism and phosphorus acquisition efficiency in common bean. Funct. Plant Biol. 31: 959-970.

Lynch, J., and J.J. van Beem. 1993. Growth and architecture of seedling roots of common bean genotypes. Crop Sci. 33:1253-1257.

Lynch, J., E. Epstein, A. Lauchli, and G.I. Weigt. 1990. An automated greenhouse sand culture system suitable for studies of P nutrition. Plant Cell Environ. 13:547-554.

Lynch, J.P., and S.E. Beebe. 1995. Adaptation of beans (Phaseolus vulgaris L.) to low phosphorus availability. HortScience 30:1165-1171.

Lynch, J.P., and K.M. Brown. 2001. Topsoil foraging-an architectural adaptation of plants to low phosphorus availability. Plant Soil 237: 225-237.

Lynch, J.P., and M.D. Ho. 2005. Rhizoeconomics: Carbon costs of phosphorus acquisition. Plant Soil 269:45-56.

Lynch, J.P., and K.M. Brown. 2005. Whole plant adaptations to low phosphorus availability. In B. Huang, ed. Plant-Environment Interactions, 3rd ed. Taylor and Francis, New York, in press.

Ma, Z., D.G. Bielenberg, K.M. Brown, and J.P. Lynch. 2001a. Regulation of root hair density by phosphorus availability in Arabidopsis thaliana. Plant Cell Environ. 24:459-467.

Ma, Z., T.C. Walk, A. Marcus, and J.P. Lynch. 2001b. Morphological synergism in root hair length, density, initiation and geometry for phosphorus acquisition in Arabidopsis thaliana: A modeling approach. Plant Soil 236:221-235.

Mano, Y., M. Muraki, M. Fujimori, T. Takamizo, and B. Kindiger. 2005. Identification of QTL controlling adventitious root formation during flooding conditions in teosinte (Zea mays ssp huehuetenangensis) seedlings. Euphytica 142:33-42.

McClean, P.E., R.K. Lee, C. Otto, P. Gepts, and M.J. Bassett. 2002. Molecular and phenotypic mapping of genes controlling seed coat pattern and color in common bean (Phaseolus vulgaris L.). J. Hered. 93:148-152.

McNamara, S.T., and C.A. Mitchell. 1990. Adaptive stem and adventitious root responses of two tomato genotypes to flooding. HortScience 25:100-103.

Miller, C.R., I. Ochoa, K.L. Nielsen, D. Beck, and J.P. Lynch. 2003.
Genetic variation for adventitious rooting in response to low phosphorus availability: Potential utility for phosphorus acquisition from stratified soils. Funct. Plant Biol. 30:973-985.

Nielsen, K.L., C.R. Miller, D. Beck, and J.P. Lynch. 1998. Fractal geometry of root systems: Field observations of contrasting genotypes of common bean (Phaseolus vulgaris L.) grown under different phosphorus regimes. Plant Soil 206:181-190.

Niklas, K.J. 1994. Plant allometry. The University of Chicago Press, Chicago, Illinois, USA.

Nodari, R.O., S.M. Tsai, R.L. Gilbertson, and P. Gepts. 1993a. Towards an Integrated Linkage Map of Common Bean.2. Development of an Rflp-Based Linkage Map. Theor. Appl. Genet. 85:513-520.

Nodari, R.O., S.M. Tsai, P. Guzman, R.L. Gilbertson, and P. Gepts. 1993b. Toward an integrated linkage map of common bean.3. Mapping genetic-factors controlling host-bacteria interactions. Genetics 134:341-350.

Olsen, S.R., and L.E. Sommers. 1982. Phosphorus. In Methods of soil analysis, part 2, Chemical and microbiological properties. p. 403430. ASA-SSSA, Madison, WI, USA.

Price, A.H., and A.D. Tomos. 1997. Genetic dissection of root growth in rice (Oryza sativa L.). II: Mapping quantitative trait loci using molecular markers. Theor. Appl. Genet. 95:143-152.

Price, A.H., K.A. Steele, B.J. Moore, and R.G.W. Jones. 2002. Upland rice grown in soil-filled chambers and exposed to contrasting waterdeficit regimes. II. Mapping quantitative trait loci for root morphology and distribution. Field Crops Res. 76:25-43.

Ragothama, K.G. 2005. Phosphorus and plant nutrition: An overview, p. 355-378. In J. T. Sims and A. N. Sharpley (ed.) Phosphorus: Agriculture and the environment. ASA, CSSA, and SSSA, Madison, WI.

Rychter, A.M., and M. Mikulska. 1990. The relationship between phosphate status and cyanide-resistant respiration in bean roots. Physiol. Plant. 79:663-667.

SAS. 1985. SAS user's guide: Statistics SAS Institute, Inc., Cary, NC.

Singh, S.P. 1982. A key for identification of different growth habits of Phaseolus vulgaris L. Annu. Rpt. Bean Improv. Coop. 25:92-94.

Singh, S.P., P. Gepts, and D.G. Debouck. 1991a. Races of common bean (Phaseolus vulgaris, Fabaceae). Econ. Bot. 45:379-396.

Singh, S.P., J.A. Gutierrez, A. Molina, C. Urrea, and P. Gepts. 1991b. Genetic diversity in cultivated common bean: II. Markerbased analysis of morphological and agronomic traits. Crop Sci. 31:23-29.

Tuberosa, R., M.C. Sanguineti, P. Landi, M. Michela Giuliani, S. Salvi, and S. Conti. 2002. Identification of QTL for root characteristics in maize grown in hydroponics and analysis of their overlap with QTL for grain yield in the field at two water regimes. Plant Mol. Biol. 48:697-712.

Vallejos, C.E., and C.D. Chase. 1991. Extended map for the phaseolin linkage group of Phaseolus vulgaris L. Theor. Appl. Genet. 82:353-357.

Vallejos, C.E., N.S. Sakiyama, and C.D. Chase. 1992. A molecular marker-based linkage map of Phaseolus vulgaris L. Genetics 131: 733-740.

Visser, E.J.W., C. Blom, and L. Voesenek. 1996. Flooding-induced adventitious rooting in Rumex: Morphology and development in an ecological perspective. Acta Bot. Neerl. 45:17-28.

Wanke, M., I. Ciereszko, M. Podbielkowska, and A.M. Rychter. 1998. Response to phosphate deficiency in bean (Phaseolus vulgaris L.) roots. Respiratory metabolism, sugar localization and changes in ultrastructure of bean root cells. Ann. Bot. (Lond.) 82:809-819.

Westerman, R.L.E. 1990. Soil testing and plant analysis. 3rd ed. SSSA, Madison, WI.

Wortmann, C., R. Kirkby, C. Eledu, and D. Allen. 1998. Atlas of common bean (Phaseolus vulgaris L.) production in Africa. CIAT, Cali, Colombia.

Wortmann, C.S., and D.J. Allen. 1994. Constraints on bean production in Africa. Annu. Rpt. Bean Improv. Coop. 37:202-203.

Yan, X.L., J.P. Lynch, and S.E. Beebe. 1996. Utilization of phosphorus substrates by contrasting common bean genotypes. Crop Sci. 36:936-941.

Yan, X.L., H. Liao, S.E. Beebe, M.W. Blair, and J.P. Lynch. 2004. QTL mapping of root hair and acid exudation traits and their relationship to phosphorus uptake in common bean. Plant Soil 265:17-29.

Yu, K., S.J. Park, V. Poysa, and P. Gepts. 2000. Integration of simple 
sequence repeat (SSR) markers into a molecular linkage map of common bean (Phaseolus vulgaris L.). J. Hered. 91:429-434.

Zhu, J.M., S.M. Kaeppler, and J.P. Lynch. 2005a. Mapping of QTL controlling root hair length in maize (Zea mays L.) under phosphorus deficiency. Plant Soil 270:299-310.

Zhu, J.M., S.M. Kaeppler, and J.P. Lynch. 2005b. Mapping of QTL for lateral root branching and length in maize (Zea mays L.) under differential phosphorus supply. Theor. Appl. Genet. 111: 688-695.

ZiChao, L., M. Ping, L. ChunPing, Z. HongLiang, L. ZhiKang, G. YongMing, and W. XiangKun. 2005. QTL mapping of root traits in a doubled haploid population from a cross between upland and lowland japonica rice in three environments. Theor. Appl. Genet. 110:1244-1252. 